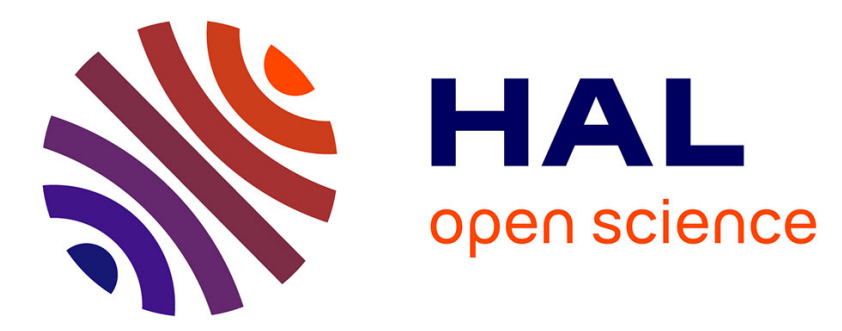

\title{
Morphology of the Ag GaSb (110) interface: a study by quantitative AES
}

A. Doukkali, J. Bonnet, L. Soonckindt, D. Mao, A. Kahn

\section{To cite this version:}

A. Doukkali, J. Bonnet, L. Soonckindt, D. Mao, A. Kahn. Morphology of the Ag GaSb (110) interface: a study by quantitative AES. Journal de Physique III, 1992, 2 (2), pp.275-285. 10.1051/jp3:1992126 . jpa-00248742

\section{HAL Id: jpa-00248742 https://hal.science/jpa-00248742}

Submitted on 1 Jan 1992

HAL is a multi-disciplinary open access archive for the deposit and dissemination of scientific research documents, whether they are published or not. The documents may come from teaching and research institutions in France or abroad, or from public or private research centers.
L'archive ouverte pluridisciplinaire HAL, est destinée au dépôt et à la diffusion de documents scientifiques de niveau recherche, publiés ou non, émanant des établissements d'enseignement et de recherche français ou étrangers, des laboratoires publics ou privés. 


\title{
Morphology of the Ag/GaSb (110) interface : a study by quantitative AES
}

\author{
A. Doukkali ( $\left.{ }^{1}\right)$, J. J. Bonnet $\left({ }^{1}\right)$, L. Soonckindt $\left({ }^{1}\right)$, D. Mao $\left({ }^{2}\right)$ and A. Kahn $\left({ }^{2}\right)$ \\ (1) Laboratoire d'Etude des Surfaces, Interfaces et Composants (L.E.S.I.C.), U.A. CNRS \\ $N^{\circ}$ D07870 - Université Montpellier, 11 Place Eugène Bataillon, 34095 Montpellier Cedex 5. \\ France \\ ( $\left.{ }^{2}\right)$ Department of Electrical Engineering, Princeton University, Princeton, NJ 08544-5263, \\ U.S.A.
}

(Received 25 June 1991, accepted 15 October 1991)

\begin{abstract}
Résumé. - Les propriétés chimiques et électroniques de l'interface $\mathrm{Ag} / \mathrm{GaSb}$ (110) formé à la température ambiante et à basse température ont été récemment étudiées au moyen de nombreuses techniques d'analyse de surface. Tous les résultats concourent pour montrer qu'à basse température et faible taux de couverture, la couche d'Ag est bidimensionnelle et probablement composée d'atomes isolés ou de clusters $2 \mathrm{D}$ très petits, alors qu'une nucléation à trois dimensions prévaut à basse température et pour des taux de couverture plus élevés, ou dès les premiers stades de la croissance à la température ambiante. L'étude quantitative de nos résultats de spectroscopie Auger confirme la croissance bidimensionnelle à basse température. Elle montre que l'évolution 3D n'est pas attribuable à une croissance de monocouches simultanées, mais plutôt à celle de clusters dont la surface de base croîtrait en moyenne linéairement avec le dépôt d'Ag.
\end{abstract}

\begin{abstract}
The chemistry and electronic properties of the $\mathrm{Ag} / \mathrm{GaSb}(110)$ interface formed at room and low temperature have been recently studied with a number of surface analysis techniques. All the results agree to show that at low temperature and at low coverage, the $\mathrm{Ag}$ layer is two dimensional and presumably composed of isolated atoms or very small $2 \mathrm{D}$ clusters, while three dimensional nucleation prevails at low temperature and higher coverage or at room temperature. Using quantitative Auger electron spectroscopy our study confirms the $2 \mathrm{D}$ growth at low temperature. It shows that the 3D evolution is not due to a simultaneous monolayer growth mechanism but agree with the enlargement of clusters whose area linearly increases with the number of impinging $\mathrm{Ag}$ atoms.
\end{abstract}

\section{Introduction.}

Many papers have been devoted to the formation of metal-III-V semiconductors interfaces during the last decade [1-6]. Experiments were performed at room (RT) and low (LT) temperature, with low energy electron diffraction (LEED), Auger electron spectroscopy (AES), electron energy loss spectroscopy (EELS), ultraviolet photoemission spectroscopy (UPS), X-ray (XPS) and soft X-ray (SXPS) photoemission spectroscopies, and Kelvin probe. The main goal of these measurements was to study the formation of Schottky barriers and to 
understand the various interactions which may take place at the metal- semiconductor interface i.e. chemical reaction, defect formation, interdiffusion, clustering. All the results were in agreement to show the importance of the morphology of the overlayer and its consequences on the semiconductor surface band bending and Fermi level pinning. The morphology strongly depends on the deposition temperature. In some cases, the RT mobility of the metal atoms and the energy of interface formation are such that the overlayer consists of $2 \mathrm{D}$ or $3 \mathrm{D}$ clusters which leave bare substrate areas for metal depositions up to several tenths of $\AA$. At LT and at low coverages, on the other hand, overlayers consist of isolated atoms or $2 \mathrm{D}$ clusters, leading to initial laminar growth. These very general results have been verified for several III-V semiconductor interfaces and, more recently [1-4] for the $\mathrm{Ag} / \mathrm{GaSb}$ (110) interface.

We propose a model based on AES results which explains the morphology of the Ag/GaSb interface. The growth parameters (i.e. the number of preliminary deposited monolayers, the initial rate of nucleation $\theta_{0}$, the speed of the cluster evolution) have been deduced from the $\mathrm{Ag}(351 \mathrm{eV})$ data. Their use is compatible with the modelisation of $\mathrm{Sb}(454 \mathrm{eV})$ and $\mathrm{Ga}$ $(1070 \mathrm{eV})$ at RT.

\section{Experiments.}

Measurements were performed on highly doped UHV cleaved GaSb (110) samples (Te, $n=1.1 \times 10^{18} \mathrm{~cm}^{-3} ; \mathrm{Zn}, p=2.8 \times 10^{18} \mathrm{~cm}^{-3}$ ) prepared with ohmic contacts [3]. Cleaving, metal deposition and measurements were done in situ, at RT and LT (35 K). Ag was evaporated from a W basket at typical rates of 1 monolayer (ML) per minute. The measurement of the flux was done with a quartz thickness monitor (the nominal thickness of a $\mathrm{Ag} \mathrm{ML}$ on $\mathrm{GaSb}(110)$ is $1.3 \AA$ ). AES measurements were done in the first derivative mode with a primary electron beam energy of $3 \mathrm{keV}$ and a peak-to-peak modulation of $0.5 \mathrm{~V}$. The electron energy analyzer was a double-pass cylindrical mirror analyzer (CMA). Ga $(1070 \mathrm{eV}), \mathrm{Sb}(454 \mathrm{eV})$ and $\mathrm{Ag}(351 \mathrm{eV})$ peaks were recorded.

\section{Model.}

AES has been extensively used for the quantitative study of adsorbed layers [7-12]. By following the evolution of the derivative $-E \mathrm{~d} N / \mathrm{d} E$ of the substrate and adsorbate Auger peaks, one obtains useful information on the growth of the deposited layer [13-18]. The analysis can be simple. However, phenomena such as dissolution of the adsorbate in the substrate, diffusion of the substrate in the adsorbed layer or formation of reacted species at the interface [19-23] can complicate the study.

Usually, the Auger electron current from the adsorbate is given by a relation assuming a simple exponential attenuation law and which can be written as

$$
I_{\mathrm{a}}(n)=I_{\mathrm{a}}(\infty)\left(1-\exp \left(-\frac{n}{\lambda_{0} \cos \alpha}\right)\right) .
$$

The subscript a stands for the adsorbate. $I_{\mathrm{a}}(\infty)$ is the Auger current from a thick crystal. $n$ is the thickness of the adsorbate in monolayers (ML); $\alpha$ is the average take-off angle of the Auger analyzer with respect to the substrate normal. $\lambda_{0}$ is the escape length of the Auger electrons in ML. For a CMA, $\cos \alpha$ is usually taken to be 0.74 . With $\lambda_{a}=\lambda_{0} \cos \alpha$, the previous equation can be rewritten

$$
I_{\mathrm{a}}(n)=I_{\mathrm{a}}(\infty)\left(1-\exp \left(-\frac{n}{\lambda_{\mathrm{a}}}\right)\right)
$$


The Auger electron current from the substrate is

$$
I_{\mathrm{s}}(n)=I_{\mathrm{s}}(0) \exp \left(-\frac{n}{\lambda_{\mathrm{s}}}\right)
$$

where the subscript $s$ stands for substrate. $\lambda_{s}$ is the escape length of the $s$ Auger electrons through the a layers.

These relations are valid approximations for uniform adsorbate layers. For a VolmerWeber growth with cylindrical clusters of identical height $n$, the Auger electron current is given by

$$
I_{\mathrm{a}}(n, \theta)=I_{\mathrm{a}}(\infty) \cdot \theta\left(1-\exp \left(-\frac{n}{\lambda_{\mathrm{a}}}\right)\right)
$$

where $\theta$ is the fraction of the surface covered by the clusters.

We will extend the previous relation to the case of an uncharacterized deposition by making the hypothesis that the adsorbate can be divided in clusters of thickness $i \mathrm{ML}$ covering a fraction $\theta_{i}$ of the surface. The Auger electron current is then :

$$
I_{\mathrm{a}}=I_{\mathrm{a}}(\infty)\left(\theta_{1}\left(1-\exp \left(-\frac{1}{\lambda_{\mathrm{a}}}\right)\right)+\cdot+\theta_{i}\left(1-\exp \left(-\frac{i}{\lambda_{\mathrm{a}}}\right)\right)+.\right)
$$

or

$$
I_{\mathrm{a}}=I_{\mathrm{a}}(\infty)\left(\sum_{l=1}^{\infty} \theta_{i}\left(1-\exp \left(-\frac{i}{\lambda_{\mathrm{a}}}\right)\right)\right)
$$

If we consider (Fig. 1) the adsorbate divided in cylindrical cristallites of height $j$ ML covering $e$ complete ML (Stransky-Krastanov growth), the current $I_{\mathrm{a}}$ becomes :

$$
I_{\mathrm{a}}=I_{\mathrm{a}} \cdot(\infty)\left(\left(1-\sum_{j=0}^{\infty} \theta_{j}\right) \cdot\left(1-\exp \left(-\frac{e}{\lambda_{\mathrm{a}}}\right)\right)+\sum_{j=0}^{\infty} \theta_{i}\left(1-\exp \left(-\frac{j+e}{\lambda_{\mathrm{a}}}\right)\right)\right)
$$

where the first term represents the contribution of the surface covered by $e$ ML and uncovered by clusters, while the second term represents the cluster contribution.

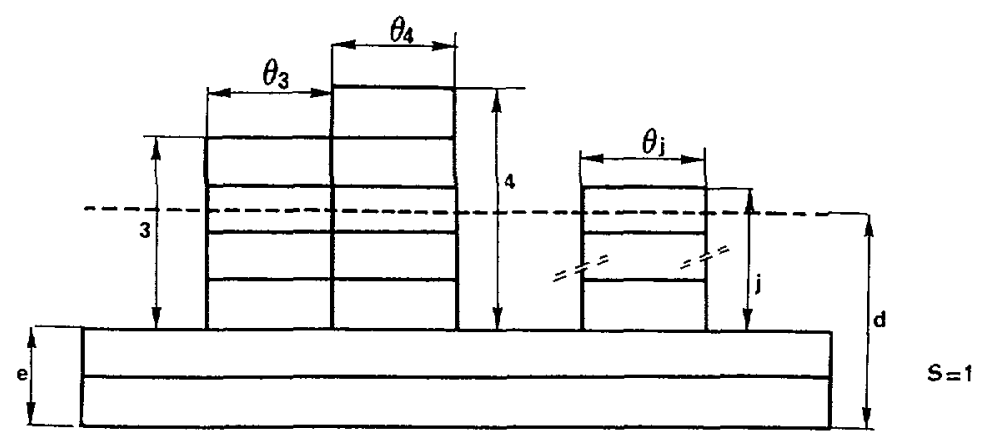

Fig. 1. - Growth model. $j$ ML thick clusters cover $e$ complete monolayers. Clusters occupy a fraction $\theta$, of the surface. The number of equivalent deposited monolayers measured with a quartz monitor is $d=\sum_{j=1}^{\infty} j \cdot \theta_{j}+e$. 
An argument similar to the previous one gives the current $I_{\mathrm{s}}$ from the substrate

$$
I_{\mathrm{s}}=I_{\mathrm{s}}(0) \cdot\left(\left(1-\sum_{j=0}^{\infty} \theta_{j}\right) \cdot \exp \left(-\frac{e}{\lambda}\right)+\left(\sum_{j=0}^{e} \exp \left(-\frac{j+e}{\lambda}\right)\right)\right)
$$

It is worth noting that the growth of simultaneous ML 124-26] on the substrate or on an intermediate ML is in fact a special case of the cluster growth mode in which the impinging atoms are presumably characterised by a Poissonian distribution and a very low surface mobility. In this mode the size of the crystallites as well as the fraction of the surface covered $\theta_{i}$ evolve with coverage : a statistical calculation shows that if $x$ atoms fall on a surface with $n$ sites, $\theta_{1}$ is given by the relation

$$
\theta_{\imath}=\left(\frac{x}{n}\right)^{\prime} \frac{1}{i !} \exp \left(-\frac{x}{n}\right)
$$

\section{Results and interpretation.}

We used this model to study the substrate-adsorbate system formed by GaSb (110) and Ag.

For Ag deposition at LT $(35 \mathrm{~K})$ the experimental results obtained for low coverages by UPS, EELS, AES and SXPS are in good agreement with a two dimensional Ag growth. This is particularly obvious from the rapid attenuation of the surface exciton [3] and surface plasmon peaks with EELS measurements. Moreover, the deconvolution of the SXPS Ga3d peak in bulk and surface components reveals that the latter disappears around $0.8 \mathrm{ML} \mathrm{Ag}$ coverage, while it persists up to $3 \mathrm{ML}$ coverage at RT.

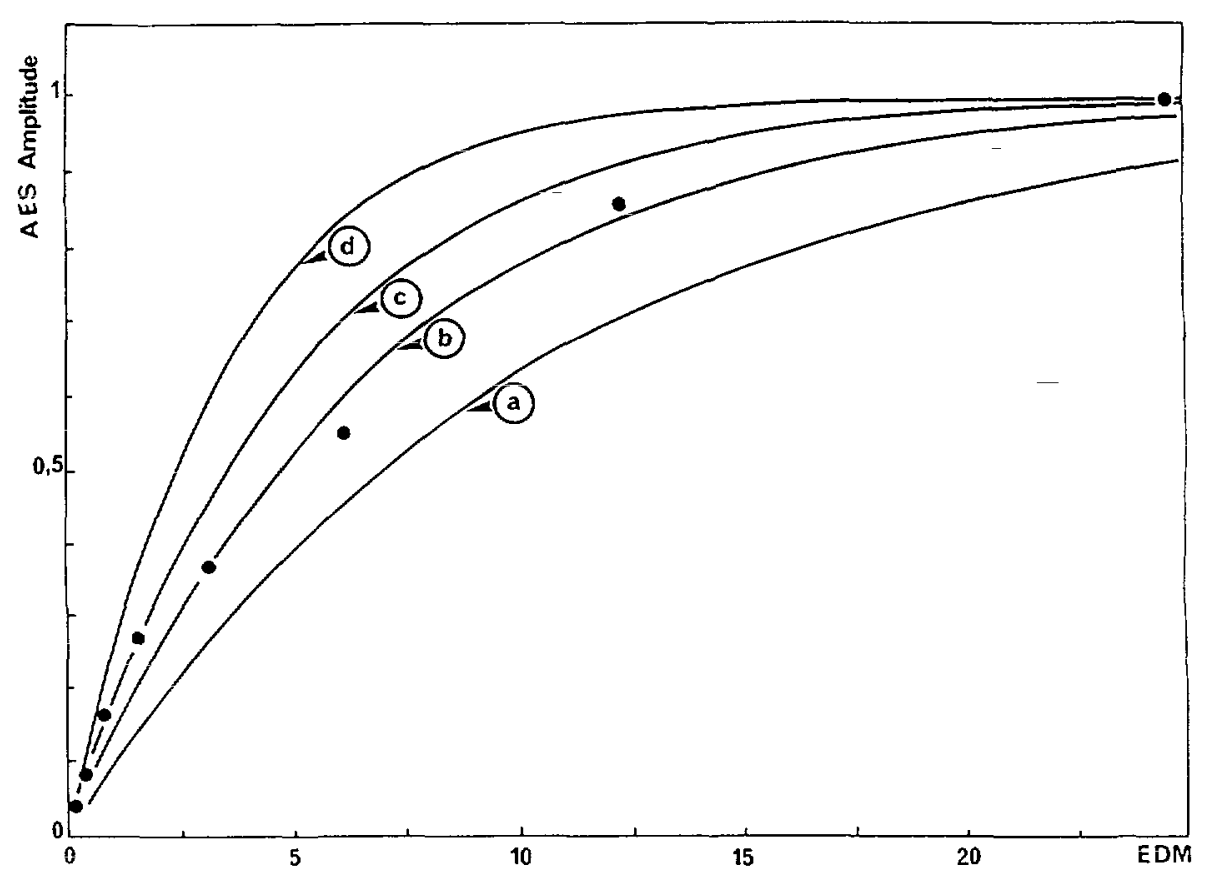

Fig. 2. - Deposition of $\mathrm{Ag}$ on $35 \mathrm{~K} \mathrm{GaSb}$ (110) with the FM mechanism hypothesis. Normalized

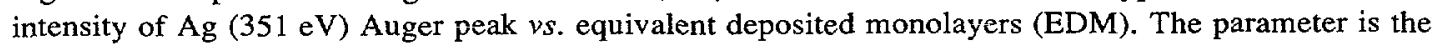
escape length $\lambda:(\bullet \bullet)$ experimental points ; $(-)$ theoretical curves. a) $\lambda=10 \mathrm{ML}$; b) $\lambda=6.7 \mathrm{ML}$; c) $\lambda=5 \mathrm{ML}$; d) $\lambda=3.3 \mathrm{ML}$. 
Following these experimental results and making the hypothesis of a layer by layer growth (Frank-van der Merwe (FM) mechanism), we have plotted the Ag Auger peak intensity for different escape lengths (Fig. 2). The only curve in agreement with the experimental values corresponds to $\lambda_{\mathrm{Ag}}=5 \mathrm{ML}$, yet, it fits the experiment for very small depositions only. At higher exposures, the Ag experimental values are lower than the theoretical ones. To explain this discrepancy we modify the previous hypothesis by introducing a Stranski-Krastanov (SK) mechanism, i.e. clusters growing on the first $2 \mathrm{D} \mathrm{ML}$. We first take a cylindrical cluster shape with a constant basis. Keeping $\lambda_{\mathrm{Ag}}=5 \mathrm{ML}$, we vary the fraction of the surface covered by the clusters $\theta_{0}$, between 0.2 and 0.8 . The result is given in figure 3. Except for low coverages ( $\leqslant 1 \AA \mathrm{Ag}$ ), the fit is again very poor. However, one can observe that, for high $\mathrm{Ag}$ deposition, the Auger peak height is proportional to the fraction of surface coverage.

Better results are obtained by using the simultaneous multilayer (SM) mechanism [24]. This model assumes a relation between the total deposited mass and the fraction of surface coverage, and consequently a relation between the different shapes of the crystallites during the growth. It gives better results (Fig. 4) but differences subsist between theory and experiments. Taking into account the previous remarks and the fact that the experimental curve exhibits a linear part, we hypothesize a linear variation of the basis area of the clusters with $\mathrm{Ag}$ deposition. We postulate a growth with one complete ML covered with hemispherical clusters. This crystallite growth model differs from the SM model by the fact that the impinging metal atoms falling on the first ML are not « frozen » but have a sufficient surface mean free path to eventually form bonds with other metal atoms. Then, it is possible to consider that the clusters maintain their initial shape while growing.

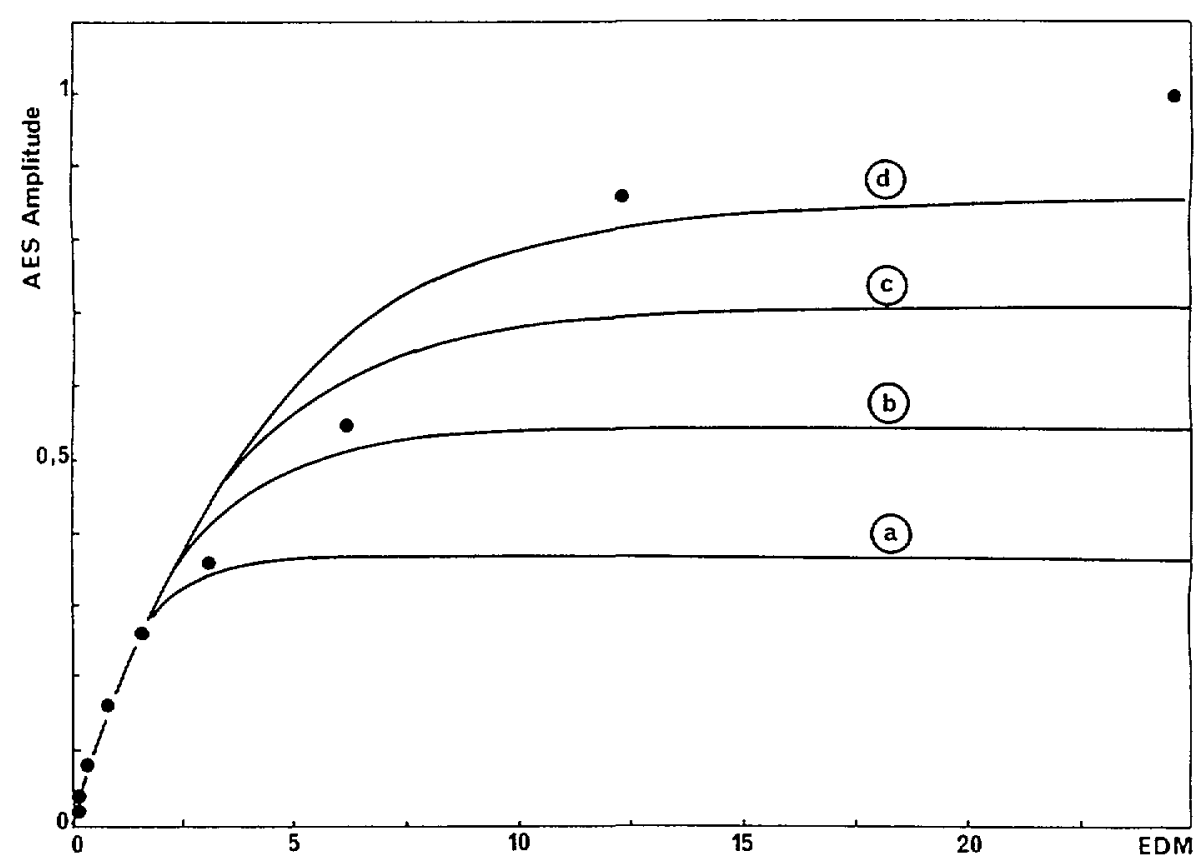

Fig. 3. - Deposition of $\mathrm{Ag}$ on $35 \mathrm{~K} \mathrm{GaSb}$ (110) with the SK mechanism hypothesis. Normalized intensity of $\mathrm{Ag}(351 \mathrm{eV}$ ) Auger peak vs. EDM. $\lambda=5 \mathrm{ML}$. The parameter is the fraction of surface coverage rate $\theta_{0}:(\bullet \bullet)$ experimental points; $(\longrightarrow)$ theoretical curves. a) $\theta_{0}=0.2 ;$ b) $\theta_{0}=0.4$; c) $\theta_{0}=0.6 ;$ d) $\theta_{0}=0.8$. 


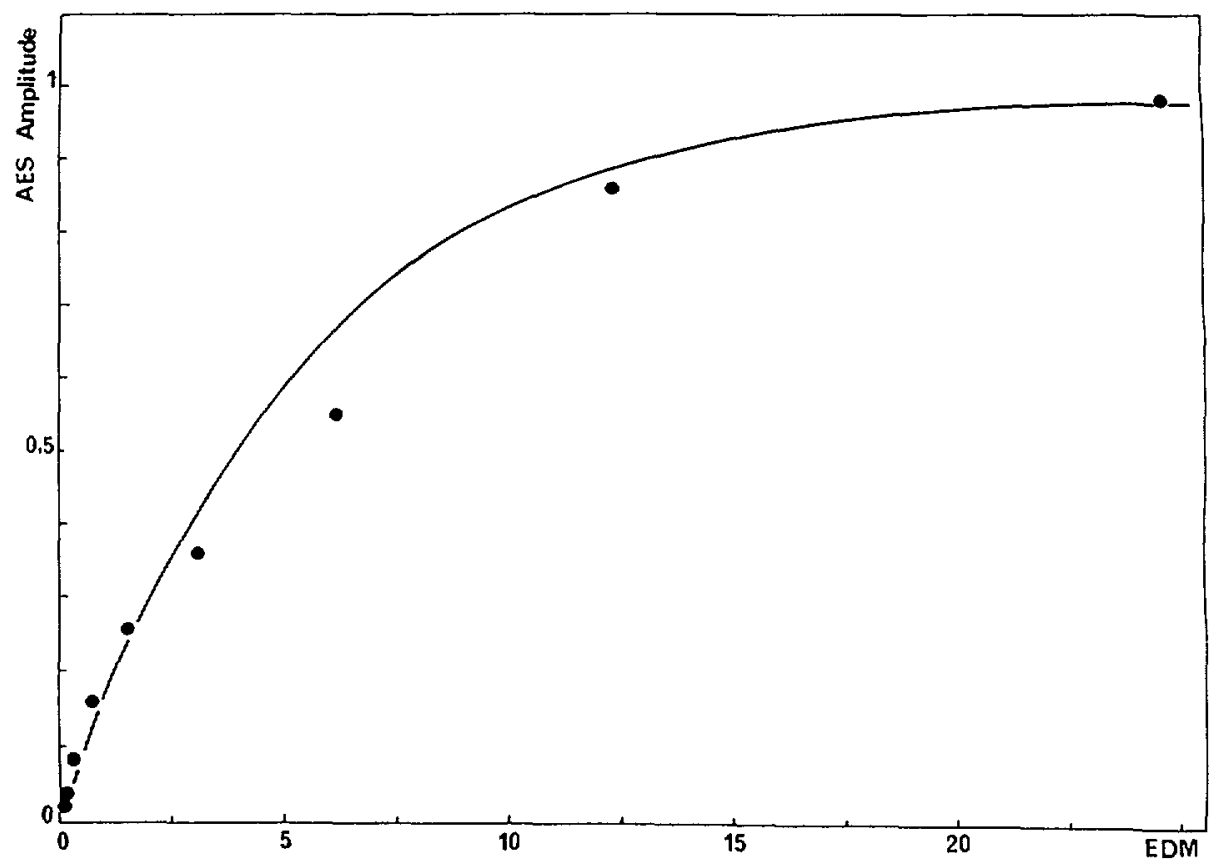

Fig. 4. - Deposition of Ag on $35 \mathrm{~K} \mathrm{GaSb}$ (110) with the SM mechanism hypothesis. Normalized intensity of $\mathrm{Ag}(351 \mathrm{eV})$ Auger peak $v s . \mathrm{EDM} . \lambda=5 \mathrm{ML}:(\bullet \bullet)$ experimental points ; $(-)$ theoretical curve.

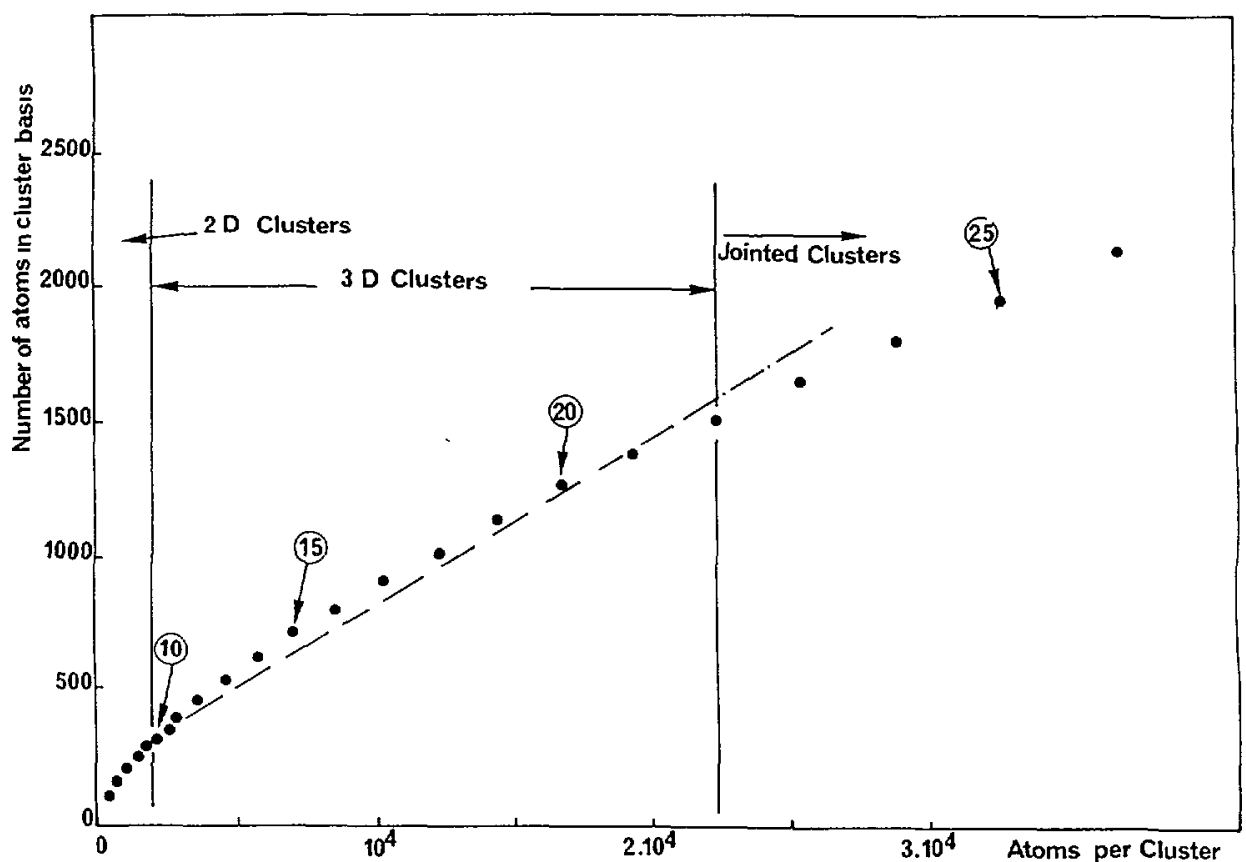

Fig. 5. - Homothetic cluster growth : evolution of the number of atoms in cluster basis $v s$. the number of atoms per cluster. In small circles $(O)$ : radius of the cluster in number of atoms. The dashed line (-) corresponds to the $V_{\theta}$ value of $0.065 / E D M$. 
For example, if $R$ is the radius of an hemispherical cluster, the volume $V$ and basis area $S$ are respectively

$$
\begin{aligned}
& V=\frac{2}{3} \pi R^{3} \\
& S=\pi R^{2}
\end{aligned}
$$

If we plot (Fig. 5) the function $S(V)$ corresponding to the surface covered by clusters versus the quantity of deposited metal, we observe a quasi-linear variation with a $V_{\theta}$ slope value of $0.065 \mathrm{ML}$ per equivalent deposited monolayer (EDM) when $R$ varies from 10 to 22, which justifies our choice of a linear variation of the covered surface vs. metal deposition.

Supposing a constant sticking coefficient equal to unity and an escape length $\lambda_{\mathrm{Ag}}=5 \mathrm{ML}$, we obtain (Fig. 6) a good agreement with experimental results. It is possible now to evaluate roughly the number of $\mathrm{Ag}$ atoms per cluster. Experimental results show that the deposition of the equivalent of $15 \mathrm{ML}$ is necessary to obtain a complete coverage of the surface. If $p$ identical jointed clusters of basis $S$ are present on a unit area of the surface, we have approximatively $: p . S=1$. The total volume of the clusters is $p \cdot V=15$. Then

$$
\frac{n V}{n S}=\frac{2 R}{3}=15
$$

and $R=22$, which corresponds approximatively to 20000 atoms per cluster and 1500 atoms directly in contact with the surface.

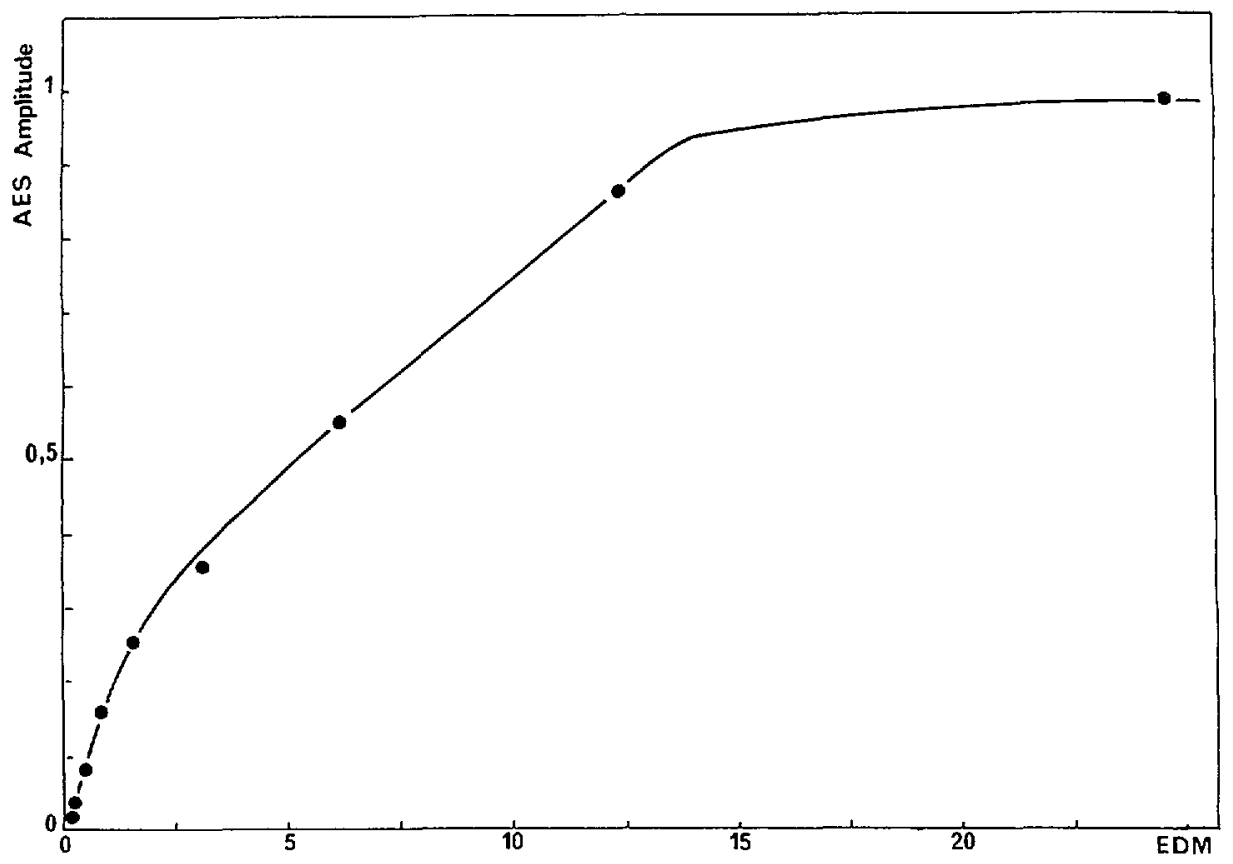

Fig. 6. - $35 \mathrm{~K} \mathrm{Ag/GaSb} \mathrm{(110)} \mathrm{deposition.} \mathrm{SK} \mathrm{mechanism} \mathrm{hypothesis.} \mathrm{With} \mathrm{clusters} \mathrm{growing} \mathrm{in} \mathrm{an}$ homothetic way on a complete monolayer. Normalized amplitude of $\mathrm{Ag}(351 \mathrm{eV})$ peak vs. EDM. $\lambda=5 \mathrm{ML}$. Parameters : cluster initial coverage rate $\theta_{0}=0.18$, growing speed of cluster coverage rate :

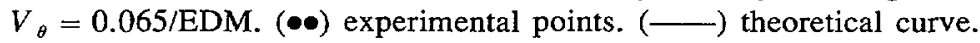




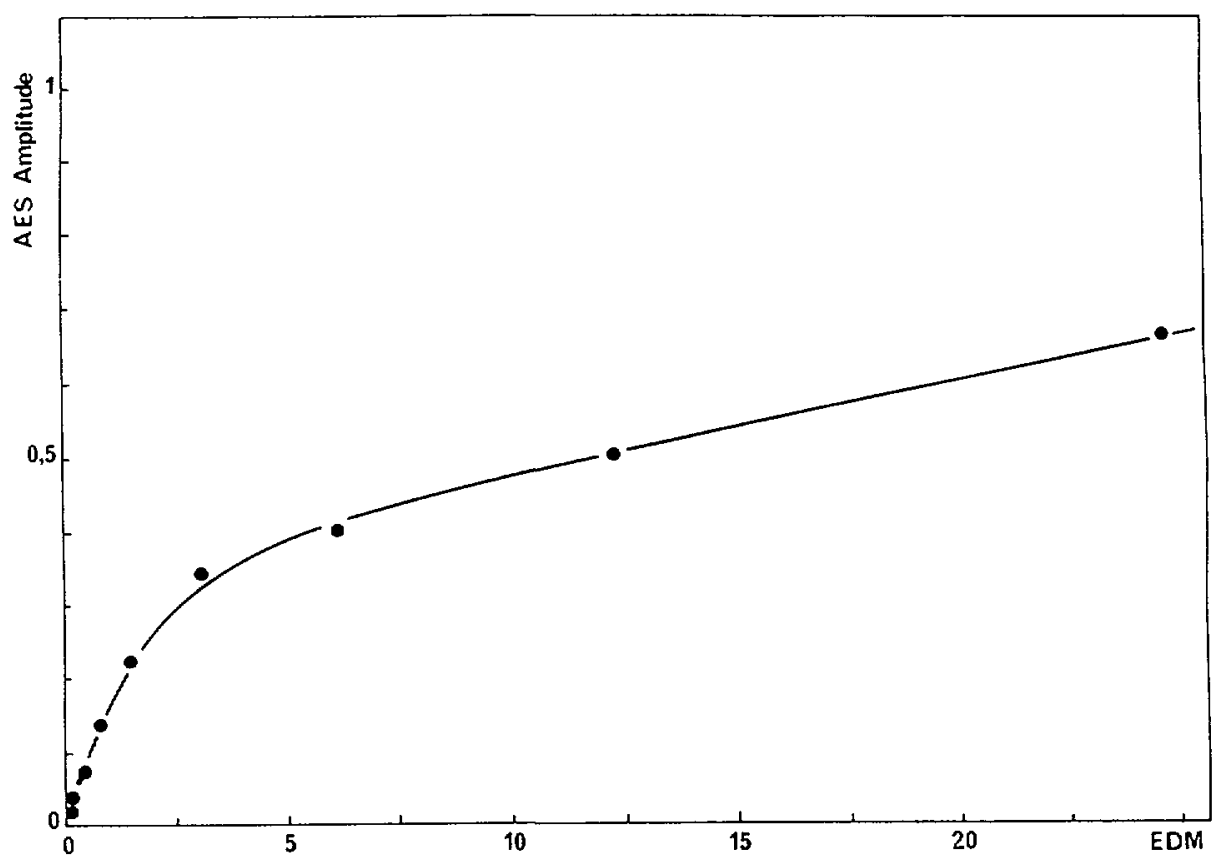

Fig. 7. - $300 \mathrm{~K} \mathrm{Ag} / \mathrm{GaSb}$ (110) deposition. SK mechanism hypothesis. With clusters growing in an homothetic way on a complete monolayer. Normalized amplitude of $\mathrm{Ag}(351 \mathrm{eV})$ peak $v s$. EDM. $\lambda=5 \mathrm{ML}$. Parameters : cluster initial coverage rate $\theta_{0}=0.32$, growing speed of cluster coverage rate : $V_{\theta}=0.013 / \mathrm{EDM}:(\bullet)$ experimental points ; $(\longrightarrow)$ theoretical curve.

At RT, the AES Sb and Ga signals are attenuated at the same rate but slower than at LT. This is characteristic of a Volmer-Weber growth : clustering produces a non-laminar growth in islands separated by uncovered areas of stoichiometric $\mathrm{GaSb}$ and the signal from these bare areas dominates because of the finite electron escape depth through the Ag islands. We have postulated a cluster growth at the very beginning of the Ag deposition. Supposing a linear variation of the fraction of surface covered with $\mathrm{Ag}$ from 0.32 to 1 with a speed of $0.013 \mathrm{ML} / \mathrm{EDM}$ and keeping an escape length $\lambda_{\mathrm{Ag}}=5 \mathrm{ML}$, we obtain (Fig. 7) a good fit with the experimental data. So, at LT as well as at RT, the final growth is due to clustering.

Obviously, the same growth parameters must be used to describe the variations of both the adsorbate and the substrate signals.

At RT, the attenuation rates of the $\mathrm{Sb}(454 \mathrm{eV})$ and $\mathrm{Ga}(1070 \mathrm{eV})$ normalized peaks are about the same (Fig. 8). Using the previous speed parameters obtained from the $\mathrm{Ag}(351 \mathrm{eV}$ ) peak study (i.e. $0.03 / \mathrm{EDM}$ ), a good fit can be obtained between experiment and theory if we take $\lambda_{\mathrm{Sb} 1}=\lambda_{\mathrm{Ga} 1}=1.4 \mathrm{ML}$ in the $0-0.7 \mathrm{EDM}$ deposure range and $\lambda_{\mathrm{Sb} 2}=\lambda_{\mathrm{Ga} 2}=6 \mathrm{ML}$ for deposure higher than 0.7 EDM. This second value of the escape length is in agreement with results found in the literature [3]. The anomalously low attenuation length of the substrate signals at the beginning of the metal deposition has been observed on GaSb surfaces with other metals such as In [27] and also on GaAs and Si in several systems : recently, Gonzales et al. ([28]; and [21-27] therein) gave a review of these discrepancies observed at low coverage and which seem to be a rather general phenomenon. The anomalous attenuations always concern the substrate signal and the effect is independent of the energy of the electrons leaving the surface. In our case the phenomenon could be linked to the difference of structure of the Ag layer during the growth. 


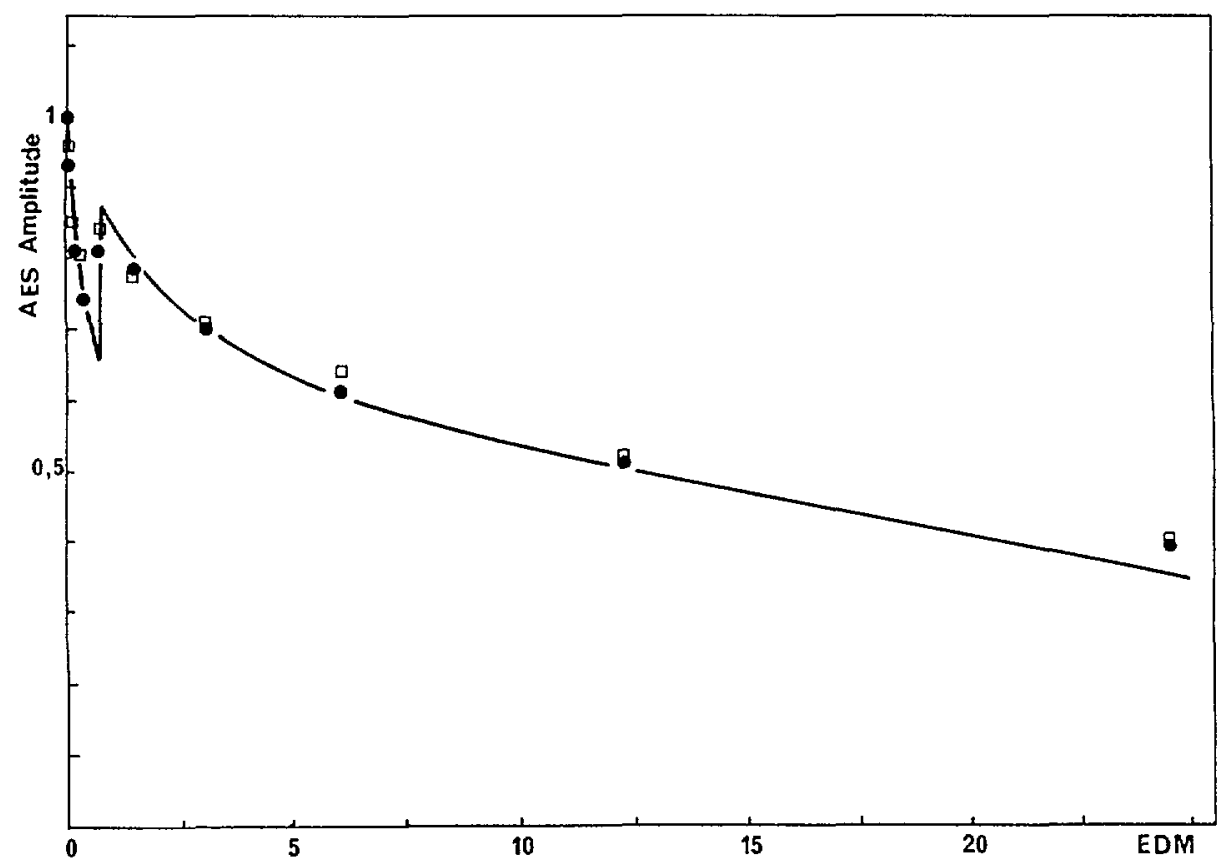

Fig. 8. - $300 \mathrm{~K} \mathrm{Ag} / \mathrm{GaSb}(110)$ deposition. Normalized amplitude of $\mathrm{Sb}(454 \mathrm{eV})$ and $\mathrm{Ga}(1070 \mathrm{eV})$ peaks vs. EDM. Growth parameters are the same as the ones used in figure 7. $\theta_{0}=0.32$; $V_{\theta}=0.013 / \mathrm{EDM}$. For a deposition lower than $0.7 \mathrm{EDM}$ the Auger escape length is $\lambda_{\mathrm{Sbl}}=\lambda_{\mathrm{Gal}}=1.4 \mathrm{ML}$. For a deposition higher or equal to $0.7 \mathrm{EDM}$, Auger length is $\lambda_{\mathrm{Sb} 2}=\lambda_{\mathrm{Ga} 2}=6 \mathrm{ML}:(\bullet)$ experimental Sb points ; ( $\left.\square \square\right)$ experimental $\mathrm{Ga}$ points ; $(\longrightarrow$ theoretical curve.

At LT, the situation is more intricate (Fig. 9) : at low deposure (under 6 EDM) a good fit between experiment and theory needs 2 different escape lengths : $\lambda_{\mathrm{Sb} 1}=\lambda_{\mathrm{Gal}}=1.4 \mathrm{ML}$ in the $0-0.7 \mathrm{EDM}$ exposure range and $\lambda_{\mathrm{Sb} 2}=2.2 \mathrm{ML}, \lambda_{\mathrm{Ga} 2}=2.8 \mathrm{ML}$ in the $0.7-6 \mathrm{EDM}$ exposure range. For higher coverages there is a discrepancy between experiment and theory whose origin could be due to the formation of reacted $\mathrm{Ga}$ and $\mathrm{Sb}$ components. In a previous paper [2] we gave some results obtained during the formation of the $\mathrm{Ag} / \mathrm{GaSb}$ (110) interface by deconvolving SXPS Ga3d and Sb4d core levels into bulk, surface and reacted components. For a coverage of $6 \mathrm{EDM}$ these latter dominate the spectra, indicating a surface disruption. $\mathrm{Ga}$ and $\mathrm{Sb}$ in the interface region could exist now in more than one chemical phase (i.e. isolated atoms, small clusters diluted in the Ag overlayer or atoms segregated on the metal surface) and this cancels the previous hypothesis concerning the morphology of the substrate : our model is then no longer valuable for exposure higher than $6 \mathrm{EDM} \mathrm{Ag.}$

The phenomenon of disruption exists at LT and RT in the same range of Ag exposure but at RT clustering leaves bare areas of GaSb up to $50 \mathrm{EDM}$ of $\mathrm{Ag}$ while at $\mathrm{LT}$ a $2 \mathrm{D}$ growth prevails at the very beginning of the deposure : this explains why our model fits the experimental data at RT for coverages up to 25 EDM while discrepancies are observed at LT.

\section{Acknowledgments.}

We would like to thank Dr. A. Gouskov for providing the GaSb ingots, Dr. L. Gouskov for performing Hall effect measurements and Mrs. V. Coronato for technical assistance. 


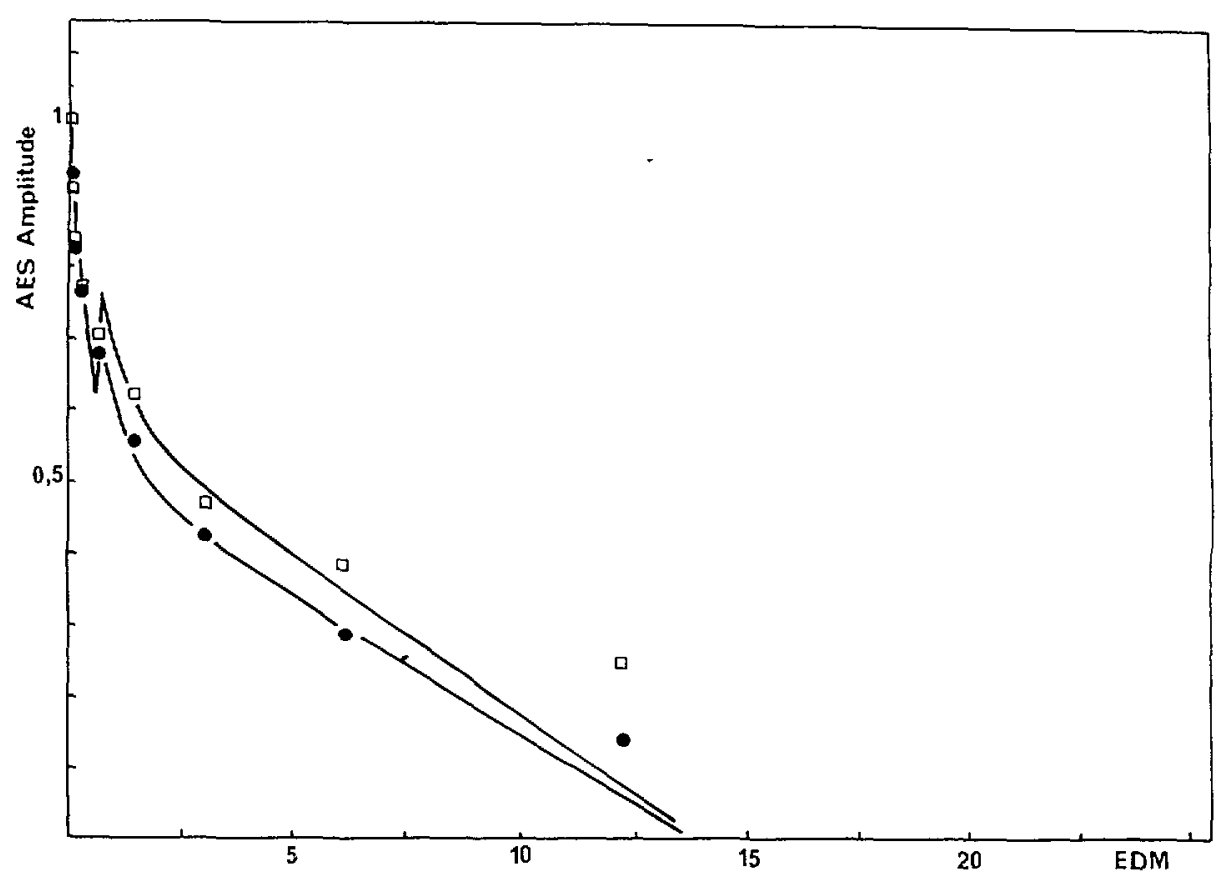

Fig. 9. - $35 \mathrm{~K} \mathrm{Ag} / \mathrm{GaSb}$ (110) deposition. Normalized amplitude of $\mathrm{Sb}(454 \mathrm{eV})$ and $\mathrm{Ga}(1070 \mathrm{eV})$ peaks vs. EDM. Growth parameters are the same as the ones used in figure 6:1 ML followed by an initial cluster initial coverage rate $\theta_{0}=0.18 ; V_{\theta}=0.065 / \mathrm{EDM}$. For a deposition lower than 0.7 EDM the Auger escape length is $\lambda_{\mathrm{Sb} 1}=\lambda_{\mathrm{Ga} 1}=1.4 \mathrm{ML}$. For a deposition higher or equal to $0.7 \mathrm{EDM}$, Auger escape length is $\lambda_{\mathrm{Sb} 2}=2.2 \mathrm{ML} ; \lambda_{\mathrm{Ga} 2}=2.8 \mathrm{ML}:(\bullet \bullet)$ experimental Sb points ; ( $\square \square$ ) experimental $\mathrm{Ga}$ points ; (-) theoretical Sb curve ; (-) theoretical Ga curve.

\section{References}

[1] Stevens K., Soonckindt L., KaHn A., J. Vac. Sci. Technol. A 8 (1990) 2068.

[2] Mao D., Soonckindt L., Kahn A., J. Vac. Sci. Technol. A 8 (1990) 1983.

[3] Mao D., Kahn A., SoOnckindt L., Phys. Rev. B 40 (1989) 5579.

[4] Bonnet J. J., Doukkali A., J. Vac. Sci. Technol. A 9 (1991) 2239.

[5] Walters S. A., Williams R. H., J. Vac. Sci. Technol. B 6 (1988) 1421.

[6] Cao R., Miyano K., Kendelewicz T., Chin K. K., Lindau I., Spicer W. E., J. Vac. Sci. Technol. B 5 (1987) 998.

[7] HaRris L. A., Surf. Sci. 69 (1977) 547.

[8] Palmberg P. W., Rhodin T. N., J. Appl. Phys. 39 (1968) 2425.

[9] Chang C. C., Surf. Sci. 48 (1975) 9.

[10] LiNCE J. R., Williams R. S., Thin Solid Films 137 (1986) 251.

[11] Pons F., Le Jericy J., Langeron J. P., Surf. Sci. 69 (1977) 547.

[12] Millo O., Many A., Goldstein Y., J. Vac. Sci. Technol. 7 (1989) 2688.

[13] Strumpler R., Luth H., Surf. Sci. 182 (1987) 545.

[14] Kahn A., Bonapace C. R., Duke C. B., Paton A., J. Vac. Sci. Technol. B 1 (1983) 613. 
[15] Aristov V. Y., Bolotin I. L., Grazhulis V. A., J. Vac. Sci. Technol. B 5 (1987) 992.

[16] Barthes G., RHEAD M. G., Surf. Sci. 80 (1979) 421.

[17] Gruzza B., GIllet E., Thin Solid Films 68 (1990) 345.

[18] Jackson D. C., Gallon T. E., Chambers A., Surf. Sci. 36 (1973) 381.

[19] Rhead G. E., Barthes M. G., Argile C., Thin Solid Films 82 (1981) 201.

[20] Venables J. A., Spiller G. D. T., Hanbucken M., Rep. Prog. Phys. 47 (1984) 399.

[21] Biberian J. P., Somorjai G. A., Appl. Surf. Sci. 2 (1979) 352.

[22] van Delft F. C. M. J. M., Langeveld A. D., Nieuwenhuys B. E., Thin Solid Films 123 (1985) 333.

[23] Ece M., Vook R. W., J. Vac. Sci. Technol. A 6 (1988) 1036.

[24] Barthes M. G., Rolland A., Thin Solid Films 76 (1981) 45.

[25] KASHCHIEV D., Surf. Sci. 86 (1979) 14.

[26] SIUdA R., Surf. Sci. 140 (1984) 472.

[27] LU Z. M., Mao D., Soonckindt L., KaHn A., J. Vac. Sci. Technol. A 8 (1990) 1988.

[28] Gonzales M. L., Alonso M., Soria F., Surf. Int. Analy. 14 (1989) 347. 